\title{
A Discourse Analysis Approach to Summary Writing
}

\section{CHARLOTTE BASHAM}

University of Alaska

\section{PAT ROUNDS}

University of Michigan

One aspect of Western academic writing which appears to cause difficulty for many for eign students is the need to report and evaluate what others within a discipline have written, without using the author's exact words. This difficulty may derive in part from a lack of skill in recognizing hierarchical structure in reading, but the fact that even skilled readers do poorly on summary writing tasks suggests that other factors must be considered as well.

In order to determine what those factors might be, we collected a group of summaries written by advanced ESL students in response to a variety of articles they read as part of their coursework for an Academic Entry English Program at the English Language Institute of the University of Michigan. Preliminary work on one set of these summaries has involved comparing the primary text (the article that the students read) with the secondary texts created by the student writers, using a system of text analysis proposed by Kintsch and van Dijk (1978). Comparison thus far has revealed three basic strategies used by students in organizing their summaries: 1) following the sequential development of the primary text, 2) including the superordinate points of the primary text but in a different order, and 3) focusing on one point in the primary text. Comparing primary and secondary texts also revealed problems in interpretation and paraphrase, specifically in determining the strength of a claim made by the primary author. Typically, the deletion or addition of modals, changes in verb tense, and the use of adverbs were found to alter not only the tone but also the intent of certain passages.

In addition to doing a comparative analysis of texts, we have examined the possibility that conflicts in underlying cultural assumptions contribute to problems which students have with summary writing. Discussions with the students have revealed that at least some of their problems stem from the nature of the task itself, including the assumption that it is possible to separate "words" from "meaning"- that is, that one can paraphrase someone else's words.

This research is intended to add to a growing body of knowledge about specific needs of foreign students in American universities and to provide a basis for developing instructional materials in this area.

\section{REFERENCE}

Kintsch, Walter, and Teun van Dijk. 1978. Toward a model of text comprehension and production. Psychological Review 85(5):363-394.

Authors' Address: c/o Basham, Cross-Cultural Communications, Alaska Native Programs, University of Alaska-Fairbanks, Fairbanks, AK 99701 